\title{
Tsunami Hazard Assessment for the Arabian Gulf from Earthquakes and Surface Landslides
}

\author{
Anawat SUPPASRI ${ }^{1}$, Panon LATCHAROTE ${ }^{2}$, Tanuspong POKAVANICH ${ }^{3}$, \\ Khaled AL-SALEM ${ }^{4}$, Abdullah Al-Enezi ${ }^{5}$, Shinji TODA ${ }^{6}$ and Fumihiko IMAMURA ${ }^{7}$ \\ ${ }^{1}$ Member of JSCE, Associate Professor, International Research Institute of Disaster Science, Tohoku University \\ (468-1 Aramaki-aza Aoba, Aoba-ku, Sendai 980-0845, Japan) \\ E-mail:suppasri@irides.tohoku.ac.jp \\ ${ }^{2}$ Member of JSCE, Postdoctoral researcher, International Research Institute of Disaster Science, Tohoku University \\ (468-1 Aramaki-aza Aoba, Aoba-ku, Sendai 980-0845, Japan) \\ E-mail:panon@irides.tohoku.ac.jp \\ ${ }^{3}$ Associate Research Scientist, Kuwait Institute for Scientific Research \\ (P.O. Box 24885, Safat 13109, Kuwait) \\ E-mail:tpokavanich@kisr.edu.kw \\ ${ }^{4}$ Research Specialist, Kuwait Institute for Scientific Research \\ (P.O. Box 24885, Safat 13109, Kuwait) \\ E-mail:ksalem@kisr.edu.kw \\ ${ }^{5}$ Associate Research Scientist, Kuwait Institute for Scientific Research \\ (P.O. Box 24885, Safat 13109, Kuwait) \\ E-mail:aenezi@kisr.edu.kw \\ ${ }^{6}$ Professor, International Research Institute of Disaster Science, Tohoku University \\ (468-1 Aramaki-aza Aoba, Aoba-ku, Sendai 980-0845, Japan) \\ E-mail:toda@irides.tohoku.ac.jp \\ ${ }^{7}$ Member of JSCE, Professor, International Research Institute of Disaster Science, Tohoku University \\ (468-1 Aramaki-aza Aoba, Aoba-ku, Sendai 980-0845, Japan) \\ E-mail:imamura@irides.tohoku.ac.jp
}

The Arabian Gulf (also known as Persian Gulf) region is one of the most important oil producers to fuel the world and most of the population is located along the coasts. The present study aimed, for the first time, to carry out some preliminary assessment of the tsunami hazards in the Arabian Gulf region using numerical model. This study tsunamis generated by submarine earthquakes with the earthquake magnitude $\left(M_{w}\right)$ of 8.3-9.0 along the Makran Subduction Zone (MSZ) and surface landslides with the volume of 0.5-1.0 $\mathrm{km} 3$ along Iranian coast inside the Arabian Gulf. TUNAMI model was applied in this study to predict the tsunami propagation. The model adopts the staggered leap-frog scheme to solve shallow water equations describing nonlinear long-wave theory. GEBCO 30 arc-second grid data was used as bathymetry and topography data for tsunami numerical simulation. This size of the computational grid was ascertained by many previous studies for its suitability in evaluating tsunami hazards in this region. For surface landslides, tsunami generation was simulated using a two-layer numerical model developed by solving nonlinear long-wave equations within two interfacing layers with appropriate kinematic and dynamic boundary conditions at seabed, interface, and water surface. In case of the earthquakes along MSZ, $M_{w} 8.3$ has low impact to locations inside the Arabian Gulf. $M_{w} 8.6$ has considerable impact mainly at the Gulf entrance meanwhile $M_{w} 9.0$ has high impact at the Gulf entrance and negligible impact for the whole Gulf region. In case of the surface landslides inside the Arabian Gulf, the impact is rather local but major near the sources. Detailed estimation of landslide volume, tsunami simulation using very fine topography and bathymetry data and coupling tide and tsunami wave modeling will be considered for the future works.

Key Words : tsunami hazard assessment, Arabian Gulf, earthquake, surface landslide

\section{INTRODUCTION}

In Arabian Gulf (AG), also known as Persian Gulf, region most of the population and many of the vital facilities are located along the coasts. Given the shallow nature of the AG, the level of tsunami threat is usually considered low in comparison to other areas on Indian Ocean basin's rim. Hence, only few 
studies have been carried out to evaluate tsunami hazard in this region. Nevertheless, even with low or unknown tsunami risks that impose potential hazards to coastal communities, such study is still important to sustain global economy and safety of life. The present study aimed, for the first time, at carrying out some preliminary assessments of the tsunami hazards in the AG region using numerical modeling technique. Sources of tsunami in this study are submarine earthquakes and surface landslides. The submarine earthquakes were identified to be possible at the Makran Subduction Zone (MSZ) (Fig.1) and the landslides were identified at some areas along Iranian coast inside the AG.

\section{DATA AND METHOD}

\section{(1) Earthquake induced tsunami}

Although there are three faults identified in the AG region, i.e., the Makran Subduction Zone (MSZ) 1), the Kazerun strike-slip and the Zagros mountain front $^{2)}$ (Fig.1), only the MSZ was considered to be able to be the source of the tsunami. The Zagros mountain front is a reverse fault and situated not in the sea. Therefore the earthquake from this fault is not probable to cause enough uplift or subsidence in the sea. The Kazerun strike-slip fault has maximum probable earthquake magnitude at around $M_{w} 7.2$ which is not enough to generate tsunami from this type of fault. This type of fault requires extremely large earthquake to generate such small tsunami. Example of the small tsunami generated by this type of fault is at Sumatra in 2012 when the earthquake was at $M_{w}$ 8.6. The MSZ fault was considered to generate tsunami in four cases in this study. Case E1 replicates the tsunami generated from the biggest earthquake recorded in 1945 with $M_{w} 8.3^{3)}$. Although there is no record of $M_{w}$ greater than 8.3 in this area, this study followed a previous study ${ }^{1)}$ that proposed tsunami sources from great earthquakes with $M_{w}$ up to 9.0 i.e., for the running Case E2, Case E3 and Case E4. Relationship between earthquake magnitude and fault geometry previously proposed ${ }^{4)}$ was applied as it gives smaller rupture area but higher slip and ensure the probable worst-case scenarios. Fault parameters are shown in Table 1.

Table 1 Earthquake fault parameters for the selected cases in Makran subduction zone

\begin{tabular}{|ccccc|}
\hline Case & $\boldsymbol{M}_{\boldsymbol{w}}$ & Length $(\mathbf{k m})$ & Width $(\mathbf{k m})$ & Slip $(\mathbf{m})$ \\
\hline E1 & 8.3 & 55 & 70 & $4.3-10.0$ \\
E2 & 8.3 & 55 & 80 & 8.5 \\
E3 & 8.6 & 500 & 100 & 13 \\
E4 & 9.0 & 900 & 150 & 25 \\
\hline
\end{tabular}

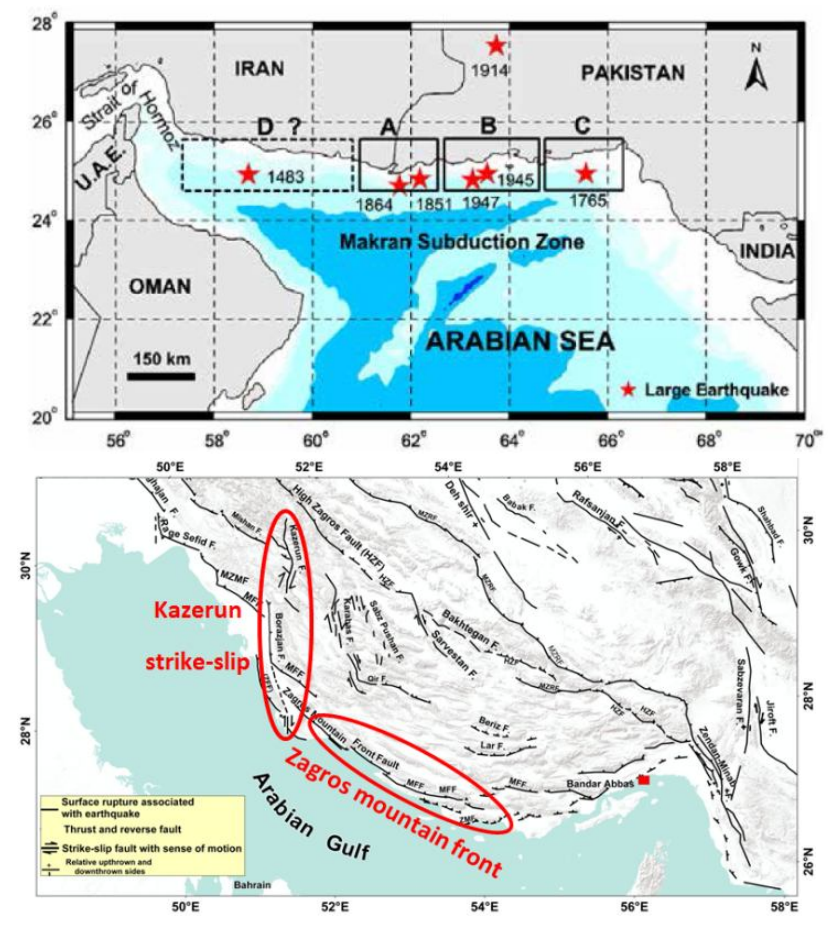

Fig.1 Up: Earthquakes along Makran Subduction Zone ${ }^{1)}$ Down: Active faults inside Arabian Gulf ${ }^{2}$

\section{(2) Landslide induced tsunami}

This study also simulated tsunami generated by surface landslides (seismically triggered by earthquakes). It is worth noting that this study for the first time investigate this phenomenon in this region. In fact, the biggest surface landslide in the world occurred inland in the region. The landslide is known as the Saidmareh landslide ${ }^{5)}$ that estimated volume of the landslide is approximately $20 \mathrm{~km}^{3}$. Five possible areas for surface landslides were identified at some the Iranian coasts where the land elevations are higher than $500 \mathrm{~m}$ and are close to the sea (Fig.2). Preliminarily, this study applied the volume of landside to 0.5 to $1 \mathrm{~km}^{3}$ based on previous studies other areas around the world. Surface landslide parameters used the five considered cases (e.g., Case L1, Case L2, Case L3, Case L4 and Case L5) in this study are shown in Table 2. Future detailed investigation is needed to verify and revisit the volumes.

Table 2 Surface landslide parameters for the assumed scenarios along Iranian coast inside the Arabian Gulf

\begin{tabular}{|ccccc|}
\hline Case & $\begin{array}{c}\text { Volume } \\
\left(\mathbf{k m}^{\mathbf{3}}\right)\end{array}$ & $\begin{array}{c}\text { Length } \\
(\mathbf{k m})\end{array}$ & $\begin{array}{c}\text { Width } \\
(\mathbf{k m})\end{array}$ & $\begin{array}{c}\text { Thickness } \\
(\mathbf{m})\end{array}$ \\
\hline L1 & 1.0 & 20 & 5 & 10 \\
L2 & 1.0 & 20 & 5 & 10 \\
L3 & 1.0 & 20 & 5 & 10 \\
L4 & 1.0 & 20 & 5 & 10 \\
L5 & 0.5 & 10 & 5 & 10 \\
\hline
\end{tabular}




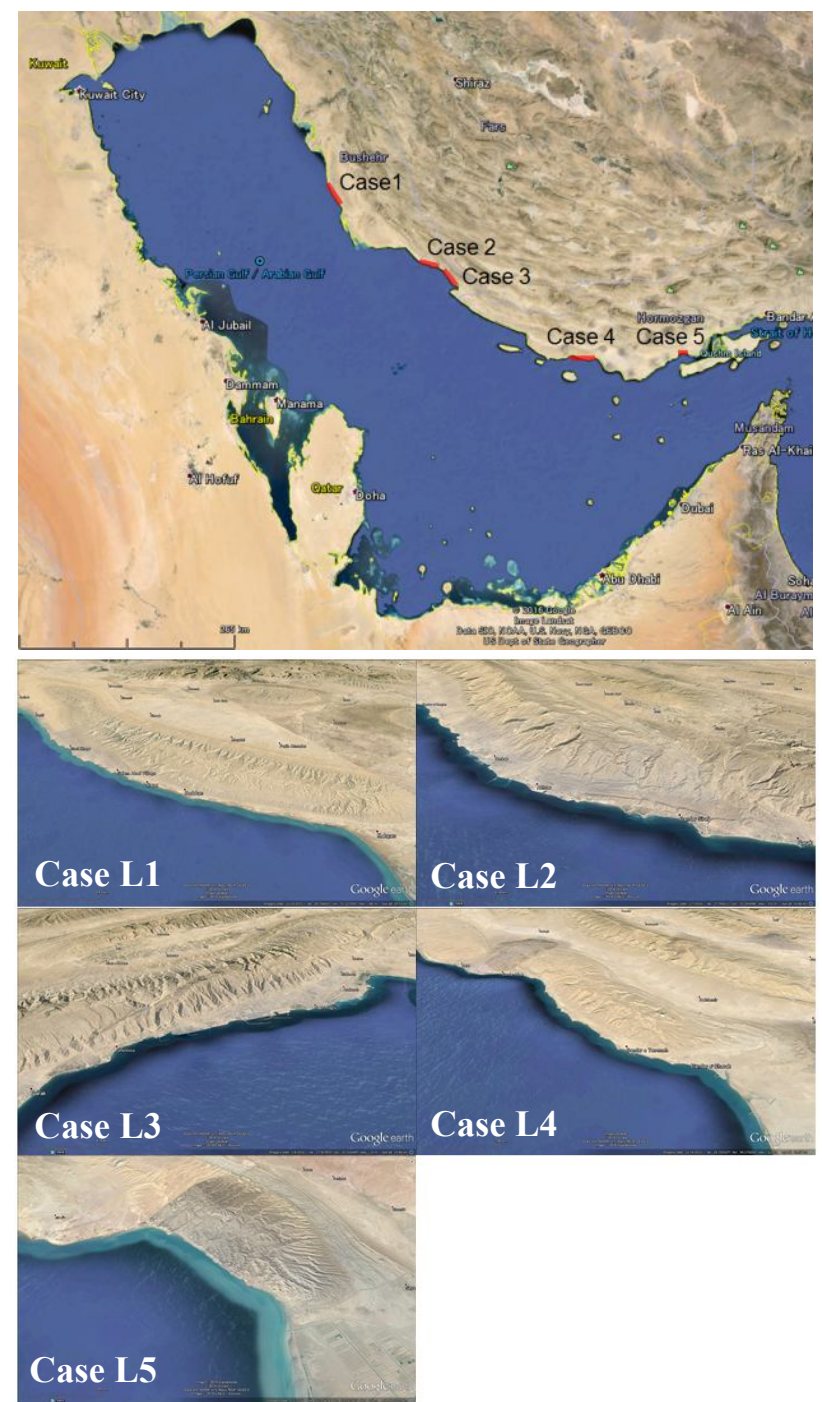

Fig.2 Locations of surface landslide in the Arabian Gulf region with the estimated slide volume of 0.5 to $1 \mathrm{~km}^{3}$

\section{(3) Tsunami numerical simulation}

TUNAMI model ${ }^{6)}$ was applied in this study to predict the tsunami propagation. The model adopts the staggered leap-frog scheme to solve shallow water equations describing nonlinear long-wave theory6). Initial sea surface conditions were prepared using formulas that calculate seafloor and coastal deformation due to submarine faulting using earthquake fault parameters ${ }^{7}$. For surface landslides, tsunami generation was simulated using the two-layer numerical model that developed by solving nonlinear long-wave equations within two interfacing layers with appropriate kinematic and dynamic boundary conditions at seabed, interface, and water surface ${ }^{8}$. A bathymetry grid of $925 \mathrm{~m}$ x $925 \mathrm{~m}$ using the 30 -arcsecond GEBCO-08 bathymetric da$\mathrm{ta}^{9)}$ was used. This grid size is appropriate since the tsunami wavelengths are estimated from the earthquake magnitude to be around $200-300 \mathrm{~km}$. This size of the computational grid was widely used in previously studies ${ }^{1), 3)}$ as it is proved to be a stable model that can be used to evaluate tsunami hazards in this region. The simulations were performed for a total simulation time of 30 and 24 hours for earthquake and surface land slide cases, respectively. It should be noted that reflective boundary condition was imposed on the shoreline at the entire area to ignore the tsunami inundation along the coast. The tsunami inundation modeling is to be carried out with finer mesh in the future work. Initial seafloor deformations were calculated from ground deformation parameters (Table 1) and estimated equation ${ }^{7}$. The results suggested that the maximum uplift is about $3 \mathrm{~m}, 3 \mathrm{~m}, 5 \mathrm{~m}$ and $9 \mathrm{~m}$ for Case E1 to E4, respectively. Initial sea level conditions of the considered four earthquake induced tsunami scenarios are shown in Fig.3.

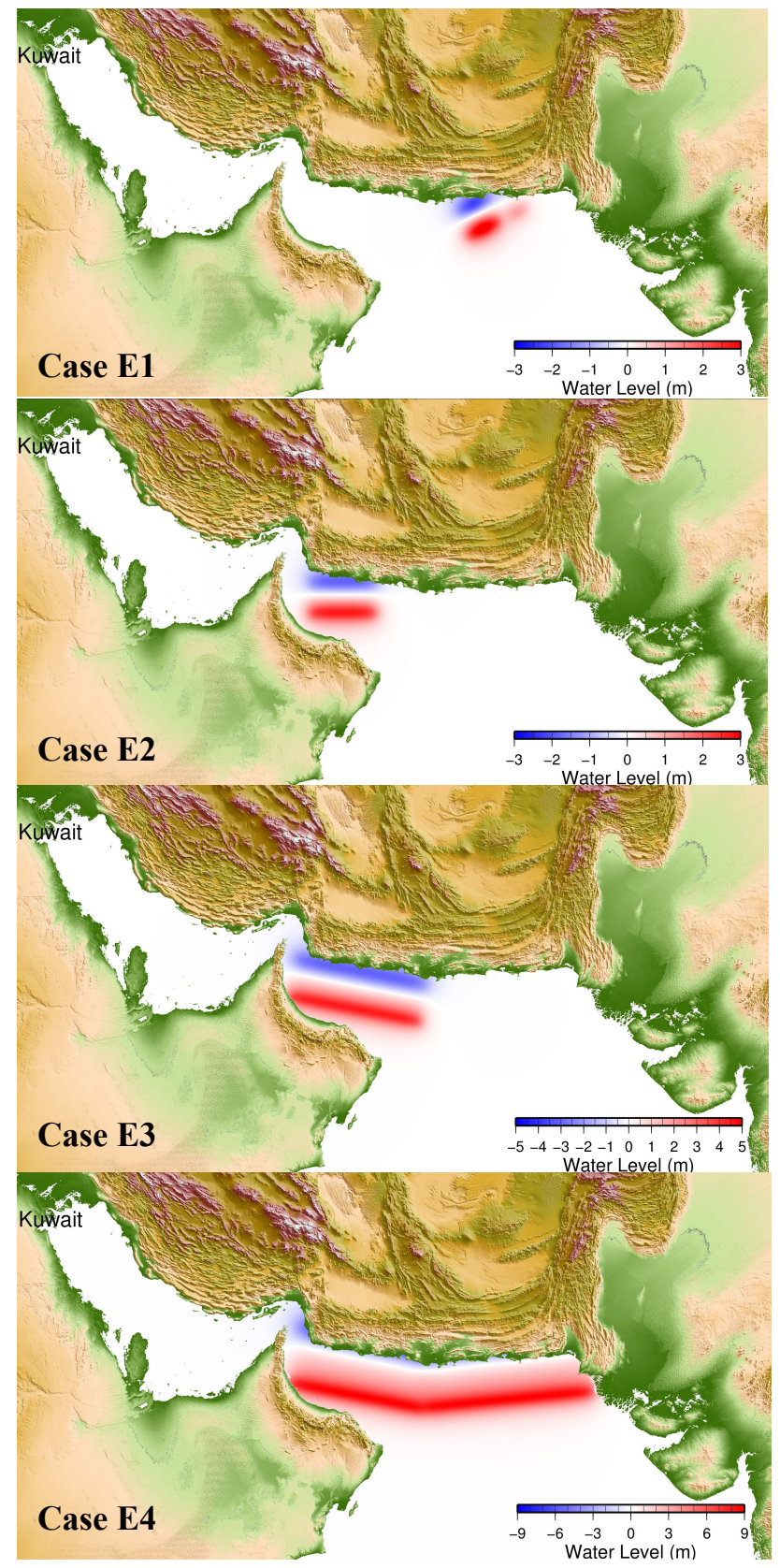

Fig.3 Initial sea level for four earthquake scenarios $\left(M_{w} 8.3-9.0\right)$ along Makran subduction zone 
Calculated sea surface deformation using the two-layer model of the landslide cases at $30 \mathrm{~min}$ elapse time from the start of the simulation for Case L1 to L5 are shown in Fig.4.

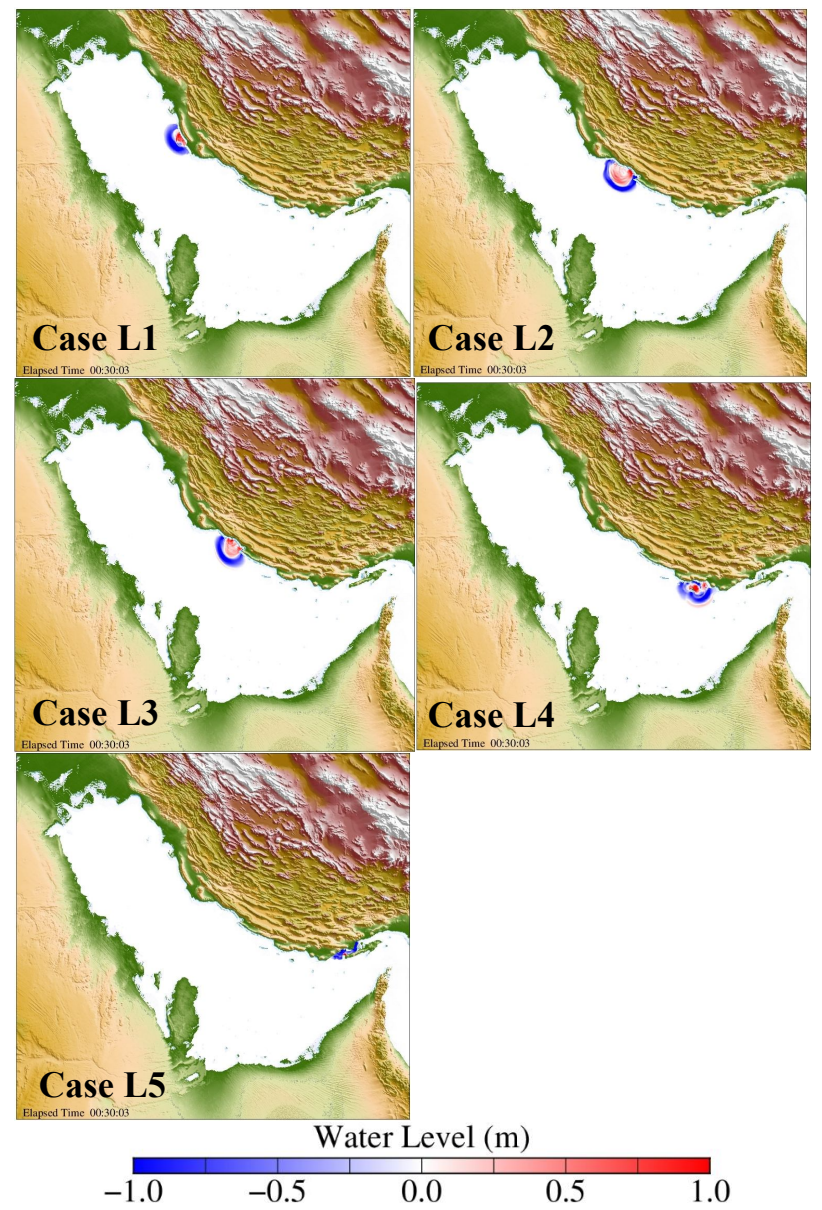

Fig.4 Water level after $30 \mathrm{~min}$ for the case of surface landslide scenarios (Cases L1-L4: $1 \mathrm{~km}^{3}$ and Case L5: $0.5 \mathrm{~km}^{3}$ ) along Iranian coast inside the Arabian Gulf

\section{RESULTS AND DISCUSSIONS}

Results suggested that there are insignificant impact of the tsunami in terms of tsunami wave height inside the AG from the Case E1 and the Case E2. The MSZ earthquake at magnitude $M_{w} 8.6$ (Case E3) causes around $1 \mathrm{~m}$ tsunami wave along the coast of the United Arab Emirates (UAE) and the earthquake at $M_{w} 9.0$ (Case E4) causes up to 2-3 $\mathrm{m}$ along the coast of UAE, $1 \mathrm{~m}$ along the coasts of Qatar (Doha) and Bahrain (Manama) and less than $0.5 \mathrm{~m}$ in Kuwait (Fig.5). The tsunami heights are rapidly decrease inside the AG. This phenomena agrees well with what can be observed elsewhere, when the tsunami wave enters to the shallow regions. In the cases of the landslides induced tsunami, it was found that the impacts are localized. Results of the landslide induced tsunami are shown in terms of the maximum tsunami height (Fig.6). The figures suggested that the maximum tsunami heights along the coasts are $1.35 \mathrm{~m}$ for UAE (Case E4), $2.17 \mathrm{~m}$ for Qatar (Case E2), $0.90 \mathrm{~m}$ for Bahrain (Case E2) and $0.24 \mathrm{~m}$ for Kuwait (Case E1).
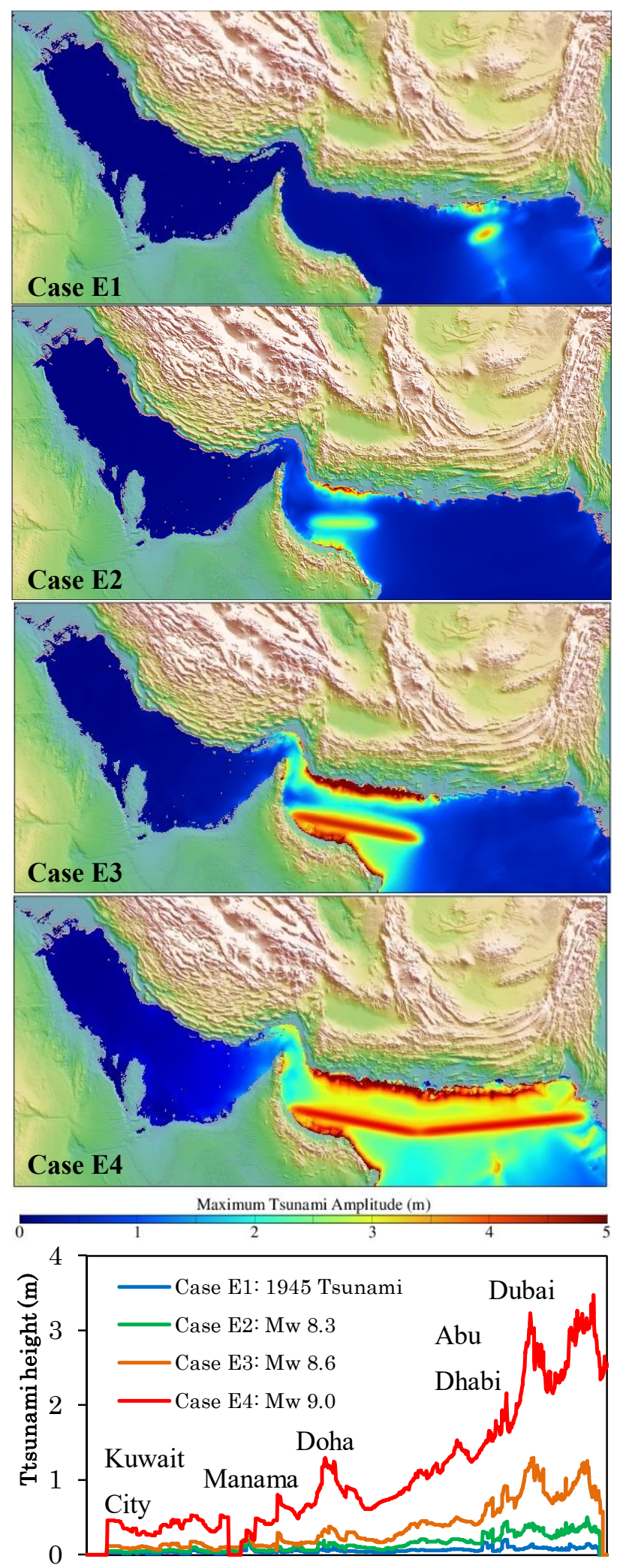

Fig.5 Distribution of the simulated maximum tsunami height by earthquakes $\left(M_{w}\right.$ 8.3-9.0) along Makran subduction zone and the simulated maximum tsunami height in major cities along the southern part of the Gulf. 


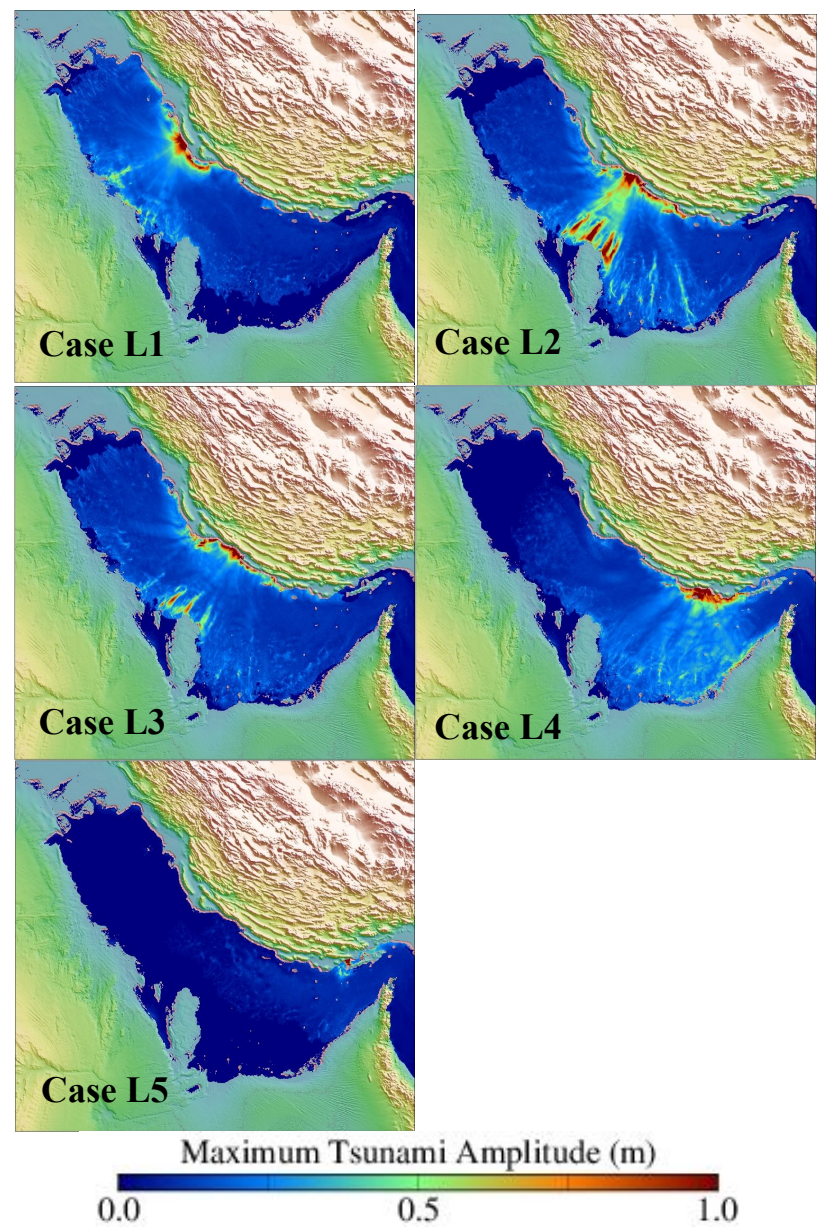

Fig.6 Simulated maximum tsunami height by surface landslides (Cases L1-L4: $1 \mathrm{~km}^{3}$ and Case L5: $0.5 \mathrm{~km}^{3}$ ) along Iranian coast inside the Arabian Gulf.

Power and desalination plants are essential of most important source of the electricity and freshwater supplies. This study provides an estimated maximum tsunami height induced by different scenarios considered in this study. Table 3 summarizes locations of important power plants ${ }^{10)}$ in countries surrounding the Arabian Gulf and the simulated maximum tsunami height from different simulation cases. This study also can conclude that the maximum tsunami heights predicted from different scenarios in this study at major power and desalination facilities are 0.04-0.50 $\mathrm{m}$ in Kuwait, $0.18-1.35 \mathrm{~m}$ in Saudi Arabia, 0.8-0.90 $\mathrm{m}$ in Bahrain, 0.27-2.17 $\mathrm{m}$ in Qatar, 0.46-3.47 m in UAE, and 0.65-3.74 in Iran.

\section{CONCLUSIONS}

This study identify three major tectonic faults in the AG regions. It was found that only one fault, the Makran Subduction Zone (MSZ), situate outside the AG can potentially cause the submarine earthquake induced tsunami. The earthquake at MSZ were studied between the magnitudes of $M_{w} 8.3$ to $M_{w}$ 9.0.
It was found that only the tsunami generated by $M_{w}$ 9.0 earthquake could yield significant impact to the whole $\mathrm{AG}$ region having maximum tsunami height of around 2-3 $\mathrm{m}$ at the mount of the AG and decrease to less than $1 \mathrm{~m}$ at the inner-most part of the AG. This study also investigate the landslide induced tsunami. Results suggested that the landslides and only cause some localized impact however can produce tsunami height as large as 3-4 m inside the AG. It is worth noting that this study preliminarily calculated landslide induced tsunami assuming some simple volume, e.g., landslide volume varies between 0.5-1.0 $\mathrm{km}^{3}$. When considering tsunami hazards at major power plants from both earthquake and landslide scenarios, the dominant tsunami height is varied by locations. The maximum tsunami heights at power plants that are located far from landslide sources are controlled by the $M_{w} 9.0 \mathrm{MSZ}$ earthquake.

Table 3 Maximum simulated tsunami height at power plants along the Arabian Gulf

\begin{tabular}{|c|c|c|c|c|}
\hline \multirow{2}{*}{ Country } & \multirow{2}{*}{ Location } & \multicolumn{3}{|c|}{$\begin{array}{l}\text { Simulated maximum } \\
\text { tsunami height }(\mathrm{m})\end{array}$} \\
\hline & & Case E4 & Landslide & Case \\
\hline \multirow{4}{*}{ Kuwait } & Doha & 0.46 & 0.12 & L1 \\
\hline & Mina Abdulla & 0.41 & 0.18 & $\mathrm{~L} 1$ \\
\hline & Sabiya & 0.35 & 0.04 & $\mathrm{~L} 1$ \\
\hline & $\begin{array}{l}\text { Az-zour } \\
\text { Al-kheran }\end{array}$ & 0.28 & 0.50 & $\mathrm{~L} 1$ \\
\hline \multirow{4}{*}{$\begin{array}{l}\text { Saudi } \\
\text { Arabia }\end{array}$} & Ras Al Khafji & 0.30 & 0.57 & $\mathrm{~L} 1$ \\
\hline & $\begin{array}{l}\text { Yanbu Marafiq } \\
\text { Jubail Port }\end{array}$ & 0.53 & 0.72 & $\mathrm{~L} 1$ \\
\hline & $\begin{array}{l}\text { Ras Tanura } \\
\text { Dammam }\end{array}$ & 0.58 & 1.35 & $\mathrm{~L} 1$ \\
\hline & $\begin{array}{l}\text { Al-qurayyah } \\
\text { Al-uqair }\end{array}$ & 0.33 & 0.18 & $\begin{array}{l}\mathrm{L} 1, \\
\mathrm{~L} 2\end{array}$ \\
\hline Bahrain & $\begin{array}{l}\text { Al-hidd } \\
\text { Al-ezzel }\end{array}$ & 0.80 & 0.90 & $\mathrm{~L} 2$ \\
\hline \multirow{3}{*}{ Qatar } & Ras Laffan & 1.25 & 2.17 & L2 \\
\hline & Ras Abu Fontas & 1.14 & 0.52 & $\mathrm{~L} 2$ \\
\hline & Mesaieed & 1.01 & 0.27 & $\mathrm{~L} 2$ \\
\hline \multirow{5}{*}{ UAE } & $\begin{array}{l}\text { Ruwais } \\
\text { Shuweihat }\end{array}$ & 0.89 & 0.46 & $\mathrm{~L} 2$ \\
\hline & $\begin{array}{l}\text { Al Taweelah } \\
\text { Jebal Ali }\end{array}$ & 3.23 & 1.35 & L4 \\
\hline & $\begin{array}{l}\text { Sharjah } \\
\text { Layyah }\end{array}$ & 2.47 & 0.93 & L4 \\
\hline & Ras Al Khaimah & 3.47 & 0.77 & $\mathrm{~L} 4$ \\
\hline & Ghalilah & 2.34 & 0.34 & $\mathrm{~L} 4$ \\
\hline \multirow{4}{*}{ Iran } & Bushehr & 0.68 & 1.08 & $\mathrm{~L} 1$ \\
\hline & Dorud & 0.80 & 1.81 & $\mathrm{~L} 1$ \\
\hline & $\begin{array}{l}\text { Kangan } \\
\text { Tombak }\end{array}$ & 0.84 & 3.74 & L2 \\
\hline & Asaloyeh & 0.65 & 3.52 & $\mathrm{~L} 2$ \\
\hline
\end{tabular}


Future works include detailed analysis on possible landslide volume and locations from detailed calculation which will take into account the geotechnical conditions e.g., land elevation, soil data. Furthermore, more accuracy of tsunami numerical simulation can be enhanced by applying finer grid and input bathymetry data at the AG, include the tsunami inundation, etc. Last but not least, the authors plan to incorporate effects of natural tide in the $\mathrm{AG}$ to the tsunami simulation considering the complex tidal characteristics of the AG and over 10 hour travel time of tsunami wave from the MSZ source to the inner-part of the AG.

ACKNOWLEDGMENT: The study is part of the joint research project between the International Research Institute of Disaster Science (IRIDeS), Tohoku University and Kuwait Institute for Scientific Research (KISR) jointly funded by Kuwait Foundation for the Advancement of Sciences (KFAS) (Project code: P214-44SE-01) and KISR. We would like to thank Dr. Kenji Harada (Shizuoka University), Dr. Shuji Moriguchi (Tohoku University), Prof. Takashi Kyoya (Tohoku University) for their valuable advices on the landslide induced tsunami part.

\section{REFERENCES}

1) Heidarzadeh, M., Pirooz, M.D. and Zaker, N.H.: Modeling the near-field effects of the worst-case tsunami in the Makran subduction zone, Ocean Engineering, Vol. 36, No. 5, pp. 368-376, 2009

2) Hessami, K., Jamali, F., and Tabassi, H., 2003, Major active faults of Iran, scale 1: 2,500,000., International Institute of Earthquake Engineering and Seismology.

3) Heidarzadeh, M. and Satake, K.: New insights into the source of the Makran tsunami of 27 November 1945 from tsunami waveforms and coastal deformation data, Pure and Applied Geophysics, Vol. 172, No. 3, pp. 621-640, 2014.

4) Wells, D.L and Coppersmith K.J.: New empirical relationship among magnitude, rupture length, rupture width, rupture area and surface displacement, Bulletin of the Seismological Society of America, 84(4), 974-1002, 1994.

5) Shoaei, Z. and Ghayoumian, J.: Seimareh landslide, the largest complex slide in the world, In: Moore D and Hungr $\mathrm{O}$ (eds) the $18^{\text {th }}$ International Congress of the International Association for Engineering Geology and the Environment, 1-5, 1337-1342, 1998.

6) Imamura, F.: Review of tsunami simulation with a finite difference method, in H. Yeh, P. Liu, and C. E. Synolakis (Eds.), "Long-Wave Runup Models," pp. 25-42, Singapore: World Scientific Publishing Co., 1996.

7) Okada, Y. (1985), Surface deformation due to shear and tensile faults in a half space, Bull. Seismol. Soc. Am. 75(4), $1135-1154$.

8) Imamura, F., Imteaz, M.A.: Long waves in two-layers: governing equations and numerical model, Science of Tsunami Hazards, Vol. 13, No. 1, pp. 3-24, 1995.

9) General Bathymetric Chart of the Oceans (GEBCO), GEBCO_08 grid: http://www.gebco.net/ (Accessed date: 20 February 2009)

10) Enipedia: Portal: Power Plants: http://enipedia.tudelft.nl/wiki/Portal:Power_Plants (Accessed date: 20 May 2016)

(Received March 16, 2016) 